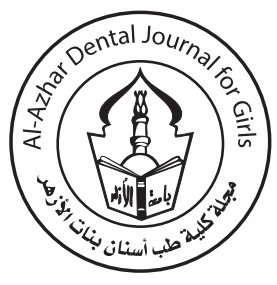

\title{
Assessment of Microbial Adherence on Conventional and CAD/CAM Complete Denture
}

\section{Dina M Kholief ${ }^{(1)}$ and Shereen M Kabeel ${ }^{(2)}$}

Codex : 01/1901

azhardentj@azhar.edu.eg

http://adjg.journals.ekb.eg

DOI: $10.21608 /$ adjg.2018.6372.1060

\section{KEYWORDS}

$C A D / C A M$, conventional denture, microbial colonization

\begin{abstract}
Purpose: The aim of the study was to assess microbial adherence on maxillary complete denture carried by different fabrication techniques; the conventional and $\mathrm{CAD} / \mathrm{CAM}$ ( computer-aided design and computer-aided manufacturing) techniques. Material and methods: Ten completely edentulous patients were selected and divided into randomly two equal groups: group I, patients received maxillary and mandibular complete dentures made of conventional heat-cured acrylic resin and group II, patients received maxillary $\mathrm{CAD} / \mathrm{CAM}$ complete denture and mandibular conventional complete denture. Assessment of the microbial colonization of maxillary dentures for both groups was carried out after 3, 6 and 9 months after denture insertion. The tested microorganisms are Candida albicans (C. albicans), Staphylococcus aureus (S. aureus), Streptococcus mutans (S. mutans) and Escherichia coli (E. coli). Results: Comparison of microbial colonization count represented in colony forming unit per $\mathrm{ml}(\mathrm{CFU} / \mathrm{ml})$. Change between group I and group II revealed that, group II has statistically significant lower $\mathrm{CFU} / \mathrm{ml}$ than group I for all the tested microorganisms during the study period (P-value $<0.05$ ) except for E. coli after 3 months the difference between both groups was statistically non significant $(\mathrm{p}=0.139)$. And there was a gradual increase in the microbial count during the time of using both types of dentures. Conclusion: CAD/CAM dentures showed less microbial colonization than conventional heat cure acrylic resin dentures. Further short-term and long-term clinical studies are needed to validate $\mathrm{CAD} / \mathrm{CAM}$ technology in complete denture prosthodontics.
\end{abstract}

\section{INTRODUCTION}

Poor oral health can adversely affect the mental, social, physical and general systemic health of denture wearers ${ }^{(1)}$. The condition of oral and denture hygiene is very important in controlling micro-organisms

1. Assistant Professor of Removable Prosthodontics, Faculty of Dental Medicine for Girls, Al-Azhar University.

2. Lecturer of Removable Prosthodontics, Faculty of Dental Medicine for Girls, Al-Azhar University. 
colonized on the denture surface ${ }^{(2)}$. A large number of complete denture wearers experienced mucosal inflammation under the denture, specially under the maxillary denture than the mandibular one. As maxillary denture is more susceptible to Candida infection causing Candida associated denture stomatitis $^{(3,4)}$.

Computer- Aided Technology (CAT) is a broad term that infers the use of computer skills to help in engineering analysis tasks. In the dentistry includes: Computer- Aided Planning (CAP), ComputerAided Design (CAD), Computer- Aided analysis (CAA), and Computer- Aided manufacturing $(\mathrm{CAM})^{(5)}$.The use of computer-aided design and computer-aided manufacturing (CAD/CAM) has been available and continues to develop in the field of fixed prosthodontics and implant prostheses ${ }^{(6-8)}$. Recently, advancements in the technology allow using different systems with CAD/CAM technology for the fabrication of removable dentures either by using milling or rapid prototyping techniques ${ }^{(9)}$.

Using CAD/CAM technique in fabrication of complete dentures has two main targets; to provide complete dentures of a better quality and to reduce the chair time. Nowadays, this is possible due to improved materials and technologies, which show advancements to conventional materials used for fabrication of complete dentures ${ }^{(10)}$. The most popular material used for denture base construction is poly-methyl-methacrylate (PMMA), which has good properties, including biocompatibility, ease of processing, stability and acceptable esthetics. However, it also has disadvantages due to remains of un-reacted monomer. This residual monomer produces toxicity and low mechanical properties and residual monomer leakage may appear, followed by generation of fissures and additional structural damage of denture base which become a point of entry for various micro-organisms ${ }^{(10,11)}$.

The implementation of computer aided technology with edentulous patients seemed to improve and simplify complete denture treatment as it significantly reduced the number of patient visits ${ }^{(12)}$. Other potential advantages include; superior strength, stored digital data, increased ability for better quality control ${ }^{(13)}$. The CAD/CAM denture failed to satisfy the patient or clinician's requirements, the clinician is capable of reverting to the conventional denture construction method, or removing the artificial teeth from the $\mathrm{CAD} /$ CAM denture. The milled denture base can be used to proceed with subsequent steps of maxillomandibular relation, trial placement, and denture processing using conventional method ${ }^{(13)}$.

A further advantage of CAD/CAM fabricated complete dentures over conventionally fabricated complete dentures is the use of a prepolymerized resin in $\mathrm{CAD} / \mathrm{CAM}$ dentures, which is manufactured under high pressure ${ }^{(14) .}$ This resin has high biocompatibility and better surface characteristics than conventional acrylic resin. Also it showed improved mechanical properties without metal or fiber reinforcement. This allows fabrication of a denture with thinner palatal plate without compromising the mechanical properties of the prosthesis, hence providing the patient with less additional volume ${ }^{(15,16)}$.

Inspite all these advantages, there are some limitations with the current CAD/CAM systems. It was difficult to establish optimal occlusal vertical dimension and maxillo-mandibular relation transfer, and the inability to define the mandibular occlusal plane. Also the high cost of the material, and increased laboratory costs compared with conventional methods ${ }^{(12)}$. Furthermore, some systems do not provide a trial denture, which is considered an important step before the final fabrication of the denture ${ }^{(17)}$.

A digitally fabricated denture has become a rapidly evolving technology, yet little information is available on their clinical or patient-centered outcomes. Therefore, the objective of the current study was to compare the microbial colonization on the surfaces of CAD/CAM and conventionally 
fabricated maxillary complete dentures. The null hypothesis was that there would be no difference between the CAD/CAM and conventionally fabricated complete denture bases regarding microbial adhesion.

\section{MATERIAL AND METHODS}

Before conducting this study, an approval was obtained from theResearch Ethics Committee (REC), Faculty of Dental Medicine for Girls, AlAzhar University. Ten completely edentulous patients were selected. Patient's age ranged from 55-65 years. Patients were selected to be free from systemic and oral diseases and with good oral hygiene. Smoker patients or those receiving any medication such as antifungal, antibiotic and antidepressant drugs in the 6 months preceding the study were excluded.All patients accepted this dental treatment, informed about the steps and signed informed consent forms before participating in this study.

The ten patients were divided into two equal groups (each group five patients). Patients in group I received maxillary and mandibular complete denture made from conventionally fabricated heat cured acrylic resin and patients in group II received maxillary CAD/CAM complete denture and mandibular conventional heat cured acrylic resin denture.

\section{A) Construction of complete dentures in group I (conventional heat cured acrylic resin)}

Preliminary impressions were made using irreversible hydrocolloid impression material. Silicone impression material (poly-C-silicone impression material, thixoflex M, medium, Zhermack, Italy)was used to make final impression after border molding with (Putty-C-Silicone). Impressions were disinfected, boxed and poured in dental stone. Maxillary cast was mounted on the articulator using maxillary face bow, and the mandibular cast was mounted using the centric jaw relation record taken from the patient at the predetermined vertical dimension of occlusion by using wax wafer technique. Crosslinked acrylic resin teeth were selected according to the patient demands then, setting-up of the artificial teeth was carried out. Waxing up was done, and the waxed up denture was checked in the patient's mouth. Denture was fabricated from heat cure acrylic resin (Acron Duo, Associated Dental Products Ltd., Kemdent, Purton, Swindon, Wiltshire, UK). Dentureprocessingwasdone using a long polymerization cycle, 9 hours in a water bath at $73^{\circ} \mathrm{C}$ $\pm 1^{\circ} \mathrm{C}$, followed by 30 minutes in boiling water as recommended by the manufacturer then, deflasking, finishing and polishing of the dentures were done following the conventional routine method. Denture delivery was carried out and the finished denture was checked for proper extension, retention and stability. The patient was given a proper program for denture insertion and oral hygiene measures. Routine follow-up appointments were scheduled for two days and one week after placement.

\section{B) Construction of complete dentures in group II (CAD/CAM denture)}

After the initial examination, the primary impressions were made with stock trays and irreversible hydrocolloid material, and the impressions were sent to a dental laboratory for the fabrication of custom trays and occlusal rim. Custom trays and occlusal rim were made on the same stone casts. The definitive impressions of the maxilla and mandible were made with the same material as in group I. Then, impressions were poured into dental stone.

Maxillo-mandibular relationship was recorded following the basic protocol for complete dentures. The master models and the occlusal rims were prepared for scanning with scan spray. Scanning was performed with an optical 3D scanner. The files from the laser-scanned master models and connected occlusal rims were translated into stereolithography (STL) files. Once the complete denture has been virtually designed in CAD software(SHERA ecomill 5x software), a preview was sent for evaluation using 3D viewing software. (Fig.1) 


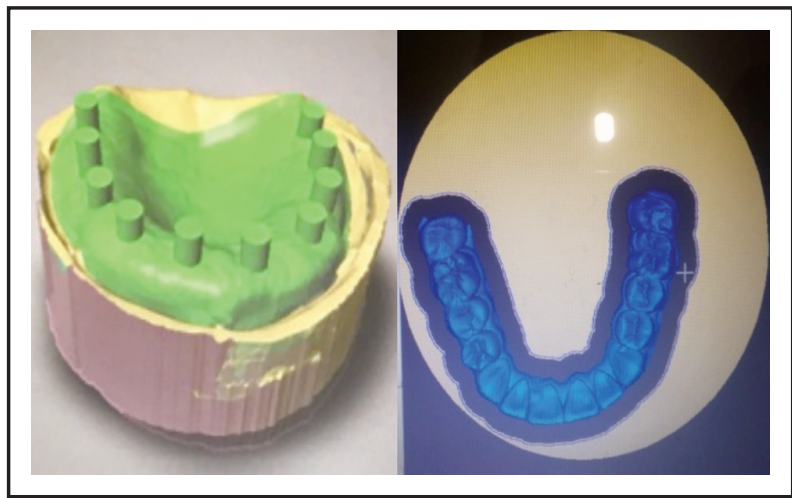

Fig. (1) Designing future denture base and future teeth templates

After minor modifications in the positions of teeth were made, fabrication of the maxillary denture was approved. The digital denture was fabricated by the command software of the milling machine (SHERA eco-mill 5x milling machine) from prepolymerized resin acrylic pucks and the teeth (TSM Acetal Dental) were milled into template (Fig.2). Teeth template bonded to pins in the denture base (Fig.3). After the denture was fabricated, it was finished and polished according to the traditional procedures (Fig.4). The mandibular denture was fabricated conventionally from heat cured acrylic resin.

After placement of the upper and lower dentures, clinical evaluation of the retention, stability, occlusal relationship, esthetics, and phonetics were performed. Assessment of the occlusion was made with articulating paper, chair-side adjustments were made and minor premature contacts were corrected. Instructions were given to the patients and routine follow-up appointments were scheduled.

\section{Microbial assessment:}

For each patient, samples were collected by swabbing the palatal mucosa as well as fitting surface of maxillary dentures using gamma sterilized disposable swabs. The swabs were taken immediately before the insertion of the denture, after 3 months, after 6 and after 9 months from insertion. The patients were instructed not to change their routine oral hygiene measures and not to take out the dentures the four hours before the sampling.

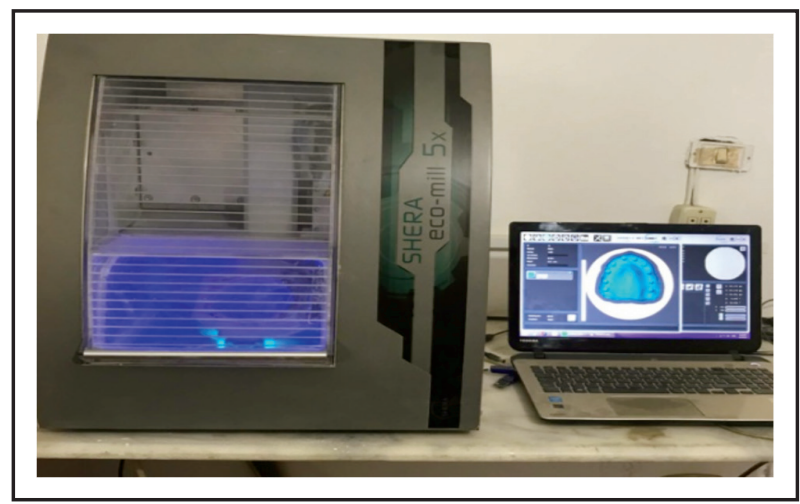

Fig. (2) Milling machine.

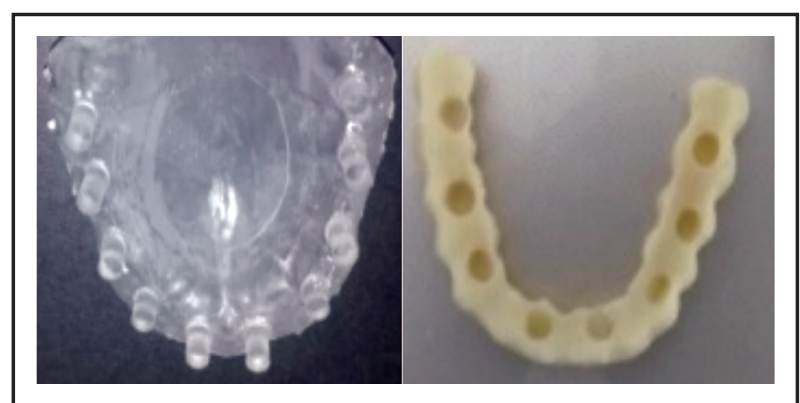

Fig. (3) Denture base template with pins and teeth template with corresponding holes.

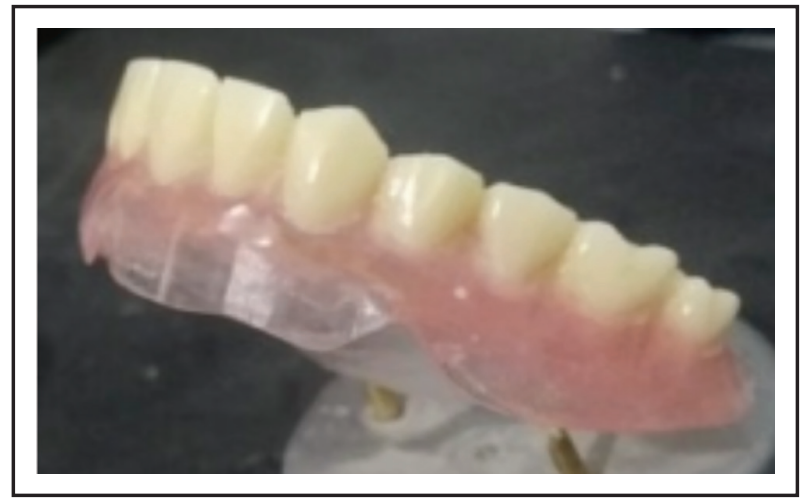

Fig. (4) Finished CAD/CAM maxillary denture.

Sterile tubes were filled with sterile saline. Five sterile tubes were used for each sample. The first tube was filled with $1000 \mu \mathrm{L}$ of sterile saline, and the other four were filled with $900 \mu \mathrm{L}$ Each swab was incubated immediately in the first sterile tube containing $1000 \mu \mathrm{L}$ of sterile saline for 15 minutes, and followed by successive dilutions at 1/10, 1/100, $1 / 1000$, and $1 / 10000$ 
Selective agars chosen for microbial cultivation included: Sabouraud's dextrose agar; these media selective for isolation of fungi, MacConkys agar; which is differential media for isolation of gram negative microorganism and blood agar base No.2; which is suitable for the cultivation of pathogens and other micro-organism. A sample of $100 \mu \mathrm{L}$ of each tube was plated on the suitable agar medium. All the microorganisms were cultured for $24 \mathrm{~h}$ at $37^{\circ} \mathrm{C}$ and the anaerobic bacteria were cultured in anaerobic containers. The tested microorganisms are Candida albicans (C. albicans), Staphylococcus aureus (S. aureus),Streptococcus mutans (S. mutans) and Escherichia coli (E. coli).

Microbial evaluation was made through counting the number of colonies on the surface of the agar gels and Colonies forming unit per $\mathrm{ml}(\mathrm{CFU} / \mathrm{ml})$ was calculated according to the following formula: $\mathrm{CFU} / \mathrm{ml}=$ total number of colonies counted in the plate $\mathrm{X}$ inversion of the saline dilution $\mathrm{X}$ inversion of the cultured volume X 1000 .

The mean difference between the microorganisms counts before insertion of the denture and after 3, 6 and 9 months for group I and group II was calculated, tabulated and statistically analyzed.

\section{Statistical analysis}

Statistical analysis was performed using Statistical Package for Social Science (IBM SPSS) version 23.The quantitative data were presented as mean, standard deviations. Independent t-test was used to compare between two independent groups with quantitative data and parametric distribution. While, repeated measure ANOVA test was used to compare between more than two paired groups with quantitative data and parametric distribution. The p-value $\leq 0.05$ was considered significant.

\section{RESULTS}

Microbial colonization count represented in $\mathrm{CFU} / \mathrm{ml}$ changes for each group was represented in table (1). There was a gradual increase in the microbial count during the time of using both the conventional acrylic resin denture and CAD/CAM dentures. Statistical analysis using ANOVA revealed that, this increase was statistically highly significant $(\mathrm{p}<0.001)$ for group I and group II.

The comparison between the mean difference and standard deviation of organisms count CFU/ $\mathrm{ml}$ in group I (conventional heat cure acrylic resin denture) and group II (CAD/CAM denture) was represented in table (2). Statistical analysis of the results using independent t-test revealed that, group II has statistically significant lower CFU/ml than group I for all the tested microorganisms at all the observation periods, except for E. coli, after 3 months the difference between both groups was statistically non significant $(\mathrm{p}=0.139)$.

Table (1) Changes in the mean difference (Mean dif.) and standard deviation (SD) of microorganisms count CFU/ml x 102in group I and II after 3, 6 and 9 months.

\begin{tabular}{|c|c|c|c|c|c|c|c|c|c|}
\hline \multirow{2}{*}{\multicolumn{2}{|c|}{ Mroups }} & \multicolumn{2}{|c|}{ After 3 months } & \multicolumn{2}{|c|}{ After 6 months } & \multicolumn{2}{|c|}{ After 9 months } & \multirow{3}{*}{$\begin{array}{c}\begin{array}{c}\text { Test } \\
\text { value• }\end{array} \\
142.123\end{array}$} & \multirow{3}{*}{$\begin{array}{c}\text { P-value } \\
<0.001^{*}\end{array}$} \\
\hline & & \multirow{2}{*}{$\begin{array}{c}\text { Mean dif. } \\
13.86 \\
\end{array}$} & \multirow{2}{*}{\begin{tabular}{c|} 
SD \\
1.62 \\
\end{tabular}} & \multirow{2}{*}{$\begin{array}{c}\text { Mean dif. } \\
19.3 \\
\end{array}$} & \multirow{2}{*}{$\begin{array}{l}\text { SD } \\
3.7 \\
\end{array}$} & \multirow{2}{*}{$\begin{array}{c}\text { Mean dif. } \\
388.2\end{array}$} & \multirow{2}{*}{$\begin{array}{c}\text { SD } \\
98.5 \\
\end{array}$} & & \\
\hline \multirow{4}{*}{ Group I } & Candida albicans & & & & & & & & \\
\hline & Strept. mutans & 52 & 16.81 & 69.66 & 14.31 & 129.3 & 33.4 & 30.707 & $<0.001 *$ \\
\hline & Staph. aureus & 38.1 & 10.4 & 58.31 & 11.2 & 154.1 & 53.2 & 37.600 & $<0.001 *$ \\
\hline & E. coli & 423.3 & 112.7 & $943 . .3$ & 302.7 & 1609 & 373.1 & 43.515 & $<0.001^{*}$ \\
\hline \multirow{4}{*}{ Group II } & Candida albicans & 11.7 & 1.24 & 14.24 & 2.9 & 98.81 & 21.3 & 153.432 & $<0.001 *$ \\
\hline & Strept. mutans & 39.23 & 7.9 & 54.78 & 10.21 & 81.45 & 11.77 & 44.819 & $<0.001 *$ \\
\hline & Staph. aureus & 25.2 & 6.5 & 37.3 & 5.7 & 96.48 & 17 & 167.171 & $<0.001 *$ \\
\hline & E. coli & 352.2 & 91.3 & 604.3 & 111.2 & 982 & 134 & 77.975 & $<0.001 *$ \\
\hline
\end{tabular}

$P$-value >0.05:Non significant (NS); P-value $\leq 0.05$ : Significant $(S) ; \quad P$-value $0 \leq 01$ : highly significant $(H S) \bullet:$ Repeated measure ANOVA test. 
Table (2) Comparison between the mean difference (Mean dif.) and standard deviation (SD) of microorganisms count CFU/ml $\times 10^{2}$ ingroup I and II after 3, 6 and 9 months.

\begin{tabular}{|c|c|c|c|c|c|c|c|}
\hline \multirow{2}{*}{\multicolumn{2}{|c|}{ Duration Micro-organism }} & \multicolumn{2}{|c|}{ Group I } & \multicolumn{2}{|c|}{ Group II } & \multirow{3}{*}{$\begin{array}{c}\begin{array}{c}\text { Test } \\
\text { value• }\end{array} \\
-2.367\end{array}$} & \multirow{3}{*}{$\begin{array}{c}\text { P-value } \\
0.045^{*}\end{array}$} \\
\hline & & \multirow{2}{*}{$\frac{\text { Mean dif. }}{13.86}$} & \multirow{2}{*}{$\frac{\text { SD }}{1.62}$} & \multirow{2}{*}{$\frac{\text { Mean dif. }}{11.7}$} & \multirow{2}{*}{$\frac{\text { SD }}{1.24}$} & & \\
\hline \multirow{4}{*}{$\begin{array}{l}\text { After } 3 \\
\text { months }\end{array}$} & Candida albicans & & & & & & \\
\hline & Strept. mutans & 52 & 16.81 & 39.23 & 7.9 & -2.174 & $0.043^{*}$ \\
\hline & Staph. aureus & 38.1 & 10.4 & 25.2 & 6.5 & -3.326 & $0.004 * *$ \\
\hline & Esch. coli & 423.3 & 112.7 & 352.2 & 91.3 & -1.550 & 0.139 \\
\hline \multirow{4}{*}{$\begin{array}{l}\text { After } 6 \\
\text { months }\end{array}$} & Candida albicans & 19.3 & 3.7 & 14.24 & 2.9 & -2.406 & $0.043^{*}$ \\
\hline & Strept. mutans & 69.66 & 14.31 & 54.78 & 10.21 & -2.677 & $0.015^{*}$ \\
\hline & Staph. aureus & 58.31 & 11.2 & 37.3 & 5.7 & -5.287 & $<0.001 * *$ \\
\hline & Esch. coli & 943.3 & 302.7 & 604.3 & 111.2 & -3.324 & $0.004 * *$ \\
\hline \multirow{4}{*}{$\begin{array}{l}\text { After } 9 \\
\text { months }\end{array}$} & Candida albicans & 388.2 & 98.5 & 98.81 & 21.3 & -9.081 & $<0.001 * *$ \\
\hline & Strept. mutans & 129.3 & 33.4 & 81.45 & 11.77 & -4.273 & $0.001 * *$ \\
\hline & Staph. aureus & 154.1 & 53.2 & 96.48 & 17 & -2.307 & $0.049^{*}$ \\
\hline & Esch. coli & 1609 & 373.1 & 982 & 134 & -5.001 & $<0.001 * *$ \\
\hline
\end{tabular}

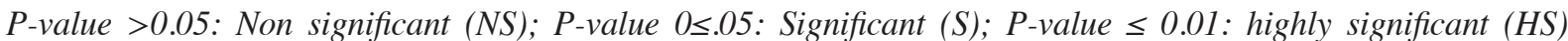
Independent t-test

\section{DISCUSSION}

Despite the exceedingly growing use of dental implants, complete dentures still represent a valuable treatment option for some edentulous individuals who cannot afford or contraindicated for implant therapy ${ }^{(18)}$. Investigating oral microflora for the removable dental prostheses wearers becomes very important ${ }^{(19)}$. The cultivable flora of the removable dental prosthesis showed a complex bacterial community, as the denture base is easily colonized by oral endogenous bacterial and Candida species and by extra-oral species. This confirms that, the removable dental prosthesis act as reservoir that harbors a mixed species of bacterial bio-film ${ }^{(20-22)}$. This microbial reservoir can be responsible for denture related stomatitis, aspiration pneumonia, infection of the amniotic fluid and cardiovascular diseases particularly bacterial endocarditis and many other life threatening infection; particularly in elder patients ${ }^{(23,24)}$.
The technology of CAD/CAM for dentures construction is promising. It allows the digitally designing and constructing of removable dentures with reduced number of patient's visits ${ }^{(25)}$. However, it is worthy to mention that CAD/CAM systems have not completely replaced traditional impression taking. Scanning of edentulous arches intraorally poses a great challenge owing to dynamic movements of the soft tissues, which influence the quality of the direct digital impression ${ }^{(26)}$.

The definitive impressions and the maxillomandibular relation can be obtained using different techniques. Improvements leading to making the definitive impression and maxillo-mandibular relation registration by using conventional manual procedures might increase the enhancement of digital complete denture technology ${ }^{(27)}$. The traditional recording method is acceptable, because of the absence of stock thermoplastic trays and jaw relation recording tools and the insufficient 
experience of clinicians with Gothic arch tracing devices and inappropriate clinical situations for their use ${ }^{(28)}$. The current study combines the advantages of CAD/CAM technology and conventional clinical recording procedures. The workflow is completely driven by CAD/CAM technology and eliminates many of the disadvantages of each laboratory step required by traditional denture fabrication and helps to simplify the work ${ }^{(29)}$.

Heat-polymerized acrylic resin was used as a control group, because it is the most popular denture base material and it has been found that heat polymerized acrylic resin has more compatible chemical properties than auto-polymerized acrylic $\operatorname{resin}^{(30)}$.

The results of the current study revealed that, there was a gradual increase in the microbial count during the time of using both the conventional acrylic resin denture and $\mathrm{CAD} / \mathrm{CAM}$ dentures. This gradual increase may be due to that, the mouth dealt with them as a foreign body thus reacting by increasing the CFU of total micro-organisms. Although, the increase of colonization of microorganisms during the follow up period might also be due to surface roughness of the materials, as aging process promotes roughness of the denture base surface ${ }^{(31)}$.

As the intra individual variations in the bacterial counting were very important. Therefore, the mean difference between the microorganisms counts before insertion of the denture and, after 3, 6 and 9 months was calculated ${ }^{(32)}$.

The null hypothesis of the current study was rejected due to the significant difference in microbial adherence between the CAD/CAM and the conventionally constructed denture bases. The affinity of cell adherence to the CAD/CAM base was less than heat cured acrylic resin, this may be explained on the fact that, surface roughness and porosity are important factors in microbial colonization; the rougher the surface and the more porosity, the greater the microbial colonization will be ${ }^{(14,33,34)}$.
Porosity in heat-cured acrylic resin denture bases is an unfavorable result. It can be caused by air trapped during mixing, monomer vaporization due to the exothermic reaction and the existence of residual monomer. Insufficient mixing of polymer and monomer, processing temperature higher than $75^{\circ} \mathrm{C}$, the way the mold is packed, and inadequate compression on the flask also may cause porosity, which may affect the adherence of micro-organism on the surface of the denture ${ }^{(35)}$.

The CAD/CAM technique has a main advantage over the conventional technique, which is the use of pre-polymerized acrylic resin block for milling the $\mathrm{CAD} / \mathrm{CAM}$ denture base ${ }^{(13)}$,which is a high-density polymers based on highly cross-linked PMMA (polymethyl methacrylate) acrylic resins. This type of cross-linked PMMA presents a decrease in the porosity and surface roughness than conventional heat cured acrylic resin ${ }^{(36)}$. In addition, CAD/CAM denture release less monomer than conventional one $^{(30)}$, due to the use of polymerized acrylic resin under special conditions, which is high pressure and temperature $^{(14,30)}$. Therefore, the CAD/CAM dentures constructed from less porous pre-polymerized PMMA acrylic resin blocks may reduce the microbial colonization, compared to conventional denture processing techniques ${ }^{(13,14,35,37)}$.

\section{CONCLUSION}

It was concluded that, complete dentures constructed with CAD/CAM technology showed promising potential for minimizing the adherence of micro-organism to the denture base surface. Further short-term and long-term clinical studies are needed to validate CAD/CAM technology in complete denture prosthodontics.

\section{REFERENCES}

1. Paranhos HFO, Peracini A, Pisani MX, Oliveira VC, Souza RF, Silva-Lovato $\mathrm{CH}$. Color stability, surface roughness and flexural strength of an acrylic resin submitted to simulated overnight immersion in denture cleansers. Braz Dent J. 2013; 24: 152-56. 
2. Köroğlu A, Şahin O, Dede DÖ, Deniz ŞT, Karacan Sever N, Özkan S. Efficacy of denture cleaners on the surface roughness and Candida albicans adherence of sealant agent coupled denture base materials. Dent Mater J. 2016; 35:810-16.

3. Ribeiro DG, Pavarina AC, Dovigo LN, Machado AL, Giampaolo ET, Vergani CE. Prevalence of Candida spp. associated with bacteria species on complete dentures. Gerodontology. 2012; 29:203-08.

4. Jackson S, Coulthwaite L, Loewy Z, Scallan A, Verran J. biofilm development by blastospores and hyphae of Candida albicans on abraded denture acrylic resin surfaces. J Prosthet Dent. 2014; 112:988-93.

5. Miyazaki T, Hotta Y, Kunii J, Kuriyama S, Tamaki Y. A review of dental CAD/CAM: current status and future perspectives from 20 years of experience. Dent Mater J.2009; 28: 44-56.

6. Reich S, Endres L, Weber C, Wiedhahn K, Neumann $\mathrm{P}$, Schneider O, et al. Three-unit CAD/CAM-generated lithium disilicate FDPs after a mean observation time of 46 months.Clin Oral Investig. 2014;18:2171-8.

7. Neves FD, Prado CJ, Prudente MS, Carneiro TA, Zancopé $\mathrm{K}$, Davi LR, et al.Micro-computed tomography evaluation of marginal fit of lithium disilicate crowns fabricated by using chair-side CAD/CAM systems or the heat-pressing technique.J Prosthet Dent. 2014;112:1134-40.

8. de França DG, Morais MH, das Neves FD, Barbosa GA. Influence of CAD/CAM on the fit accuracy of implantsupported zirconia and cobalt-chromium fixed dental prostheses.J Prosthet Dent. 2015;113:22-8.

9. Lima JM, Anami LC, Araujo RM, Pavanelli CA. Removable partial dentures: Use of rapid prototyping. J Prosthodont. 2014; 23:588-91.

10. Spasojevic P, Zrilic M, Panic V, Stamenkovic D, Seslija S, Velickovic S. The Mechanical Properties of a poly (methyl methacrylate) Denture Base Material Modified with Dimethyl Itaconate and Di-n-butyl Itaconate. Int J Polym Sci. 2015; 4: 1-9.

11. Gad MM, Fouda SM, Al-Harbi FA, Näpänkangas R, Raustia A. PMMA denture base material enhancement: a review of fiber, filler, and nano-filler addition. Int $\mathrm{J}$ Nanomedicine. 2017; 12:3801-12.

12. Bilgin M, Baytaroglu E, Erdem A, Dilber E. A review of computer-aided design/computer-aided manufacture techniques for removable denture fabrication. Eur J Dent. 2016; 10:286-91.
13. Bidra AS, Taylor TD, Agar JR. Computer-aided technology for fabricating complete dentures: systematic review of historical background, current status, and future perspectives. J Prosthet Dent. 2013; 109:361-6.

14. Al-FouzanAF, Al-MejradLA, AlbarragAM. Adherence of Candida to complete denture surfaces in vitro: a comparison of conventional and CAD/CAM complete dentures. J Adv Prosthodont. 2017; 9:402-8.

15. Koike T, Ishizaki K, Ogami K, Ueda T, Sakurai K. Influence of anterior palatal coverage on perception and retention incomplete dentures. J Prosthet Dent.2011; 105: 272-279.

16. Srinivasan M, Gjengedal H, Cattani-Lorente M, Moussa M, Durual S, Schimmel M, et al. CAD/CAM milled complete removable dental prostheses: An in vitro evaluation of biocompatibility, mechanical properties, and surface roughness. Dent Mater J. 2018; 37:526-33.

17. deMendonça AF, Furtado de Mendonça M, White GS, Sara G, Littlefair D. Total CAD/CAM Supported Method for Manufacturing Removable Complete Dentures.Case Rep Dent. 2016:1259581.

18. Jacob RF. The traditional therapeutic paradigm: complete denture therapy. J Prosthet Dent. 1998; 79:6-13.

19. Jafari AA, Tafti AF, Bafghi AF, ArzyB. The comparison of predominant oral micro-flora in subjects with and without complete denture referred to Yazd dentistry department. J Community Health Res. 2014; 3:195-203.

20. Daniluk T, Fiedoruk K, Sciepuk M, Zaremba ML, Rozkiewicz D, Cylwik-Rokicka D, et al. Aerobic bacteria in the oral cavity of patients with removable dentures. Adv Med Sci. 2006; 51:86-90.

21. Williams DW, Chamary N, Lewis MA, Milward PJ, McAndrew R. Microbial contamination of removable prosthodontic appliances from laboratories and impact of clinical storage. Br Dent J. 2011; 211:163-6.

22. Mizugai H, Isogai E, Hirose K, Chiba I. Effect of denture wearing on occurrence of Candida species in the oral cavity. J Appl Res. 2007; 7:250-4.

23. Darwazeh AM, Al-Refai S, Al-Mojaiwel S. Isolation of Candida species from the oral cavity and fingertips of complete denture wearers. J Prosthet Dent. 2001; 86:420-3.

24. Gornitsky M, ParadisI I, Landaverde G, Malo AM, Velly AM.A clinical andmicrobiological evaluation of denture cleansers for geriatric patient'sinlong-term care institutions. J Can Dent Assoc. 2002; 68:39-45. 
25. Bilgin MS, Baytaroğlu EN, Erdem A, Dilber E.A review of computer-aided design/computer-aided manufacture techniques for removable denture fabrication. Eur J Dent. 2016; 10: 286-91.

26. Bilgin MS, Erdem A, Aglarci OS, et al. Fabricating complete dentures with CAD/CAM and RP technologies. J Prosthodont. 2015; 24: 576-9.

27. Schwindling FS, Stober T. A comparison of two digital techniques for the fabrication of complete removable dental prostheses: A pilot clinical study. J Prosthet Dent. 2016; 116:756-763.

28. Kattadiyil MT, Goodacre CJ, Baba NZ. CAD/CAM complete dentures: a review of two commercial fabrication systems. J Calif Dent Assoc. 2013; 41:407-16.

29. Janeva N, Kovacevska G, Janev E. Complete dentures fabricated with CAD/CAM technology and a traditional clinical recording method. J Med Sci. 2017;5:785-789.

30. Steinmassl PA, Wiedemair V, Huck C, Klaunzer F, Steinmassl O, Grunert I, et al.Do CAD/CAM dentures really release less monomer than conventional dentures? Clin Oral Investig. 2017; 21:1697-705.

31. Darwish ET. The effect of different denture base materials on microbial flora growth. Curr Sci Int. 2017; 6: 314-20.
32. Monsenego P. Presence of microorganisms on the fitting denture complete surface: study 'in vivo'. J Oral Rehab. 2000; 27:708-13.

33. Yazici AR, Müftü A, Kugel G. Three-dimensional surface profile analysis of different types of flowable restorative resins following different finishing protocols. J Contemp Dent Pract. 2007; 8:9-17.

34. Kasina SP, Ajaz T, Attili S, Surapaneni H, Cherukuri M, Srinath HP. To evaluate and compare the porosities in the acrylic mandibular denture bases processed by two different polymerization techniques, using two different brands of commercially available denture base resins - an in vitro study.JInt Oral Health. 2014; 6:72-7.

35. Kattadiyil MT, Jekki R, Goodacre CJ, et al. Comparison of treatment outcomes in digital and conventional complete removable dental prosthesis fabrications in a predoctoral setting. J Prosthet Dent. 2015; 114:818-25.

36. Infante L, Yilmaz B, Mc Glumphy, Finger I. Fabricating complete dentures with CAD/CAM technology. J Prosthet Dent. 2014; 111:351-5.

37. Goodacre BJ, Goodacre CJ, Baba NZ, Kattadiyil MT. Comparison of denture base adaptation between CAD/ CAM and conventional fabrication techniques. J Prosthet Dent. 2016; 116:249-56. 